\title{
Shield science for robust decisions
}

\author{
Political pressure on the creation and use of scientific evidence to support environmental approvals for the \\ Adani coal mine has undermined the legitimacy of these approvals. We need to harness the power of law more \\ effectively to protect the independence and rigour of scientific processes, and enable transparent consideration \\ of the evidence.
}

\section{Erin O'Donnell and Rebecca Nelson}

\begin{abstract}
$\mathrm{n}$ a democratic society, science cannot necessarily tell us exactly what we should do, but it can very clearly lay out the consequences of the available courses of action. The call for political leaders to 'follow the science' on climate change, for instance, is not so much a call to do as science dictates, but for all of us to acknowledge that if we want the outcomes associated with our current climate, the evidence shows that we need to limit greenhouse gas emissions to prevent further global temperature rise ${ }^{1}$. Decision-makers need the best available science to understand the consequences of their choices and increase the chance that the public will accept them, particularly where behaviour change is needed. This
\end{abstract} means that the processes for generating scientific evidence must remain transparent, robust and independent.

However, the role of scientific evidence in civil society is an increasingly contested space. Even the concept of technical expertise has become embedded within the 'culture wars' of values and identity, with willingness to accept scientific evidence and expert advice strongly influenced by political leaning ${ }^{2}$. In their new Analysis, Currell et al. ${ }^{3}$ use the case of Australia's proposed Adani Carmichael Coal Mine Project ('Adani mine') to show how strong political interests in the development of the mine (which have also intersected with weakening public and political support for scientific evidence itself) undermined the independence and rigour of the evidence used to grant approval to the mine.

Currell et al. describe the Adani mine in Australia's north as "one of the largest coal mines ever proposed". Many critics have focused on associated emissions of greenhouse gases from the coal, which will make this mine one of the highest single sources of emissions. However, another potentially severe impact relates to the ancient, expansive desert oases known as 'spring complexes', sacred to the Wangan and Jagalingou peoples. These important springs

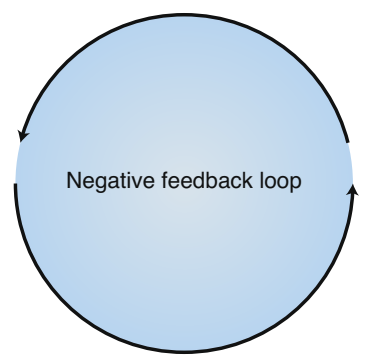

Decreasing support for scientific evidence from the public and politicians, leading to lower investment in science and poorer quality data

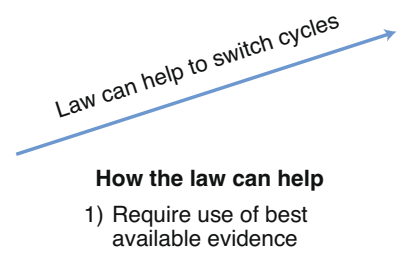

2) De-politicize evidence gathering and review

3) Increase transparency and accountability

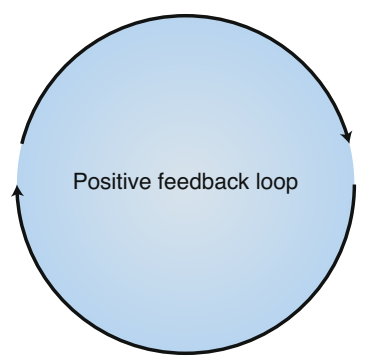

Increasing support for scientific evidence from the public and politicians, leading to increased investment in science and better quality data

Fig. 1 | Law can help break us out of a vicious cycle by protecting the scientific process. Shifting to a positive feedback loop increases support for science, which delivers better quality data, enabling decision makers to rely on the best evidence to support their decisions.

attract the highest level of protection under Australia's national environmental law. However, this level of protection has been compromised in two important ways.

Firstly, although the main approvals process for the mine involved public written submissions and independent scientific reviews and lasted over a decade, crucial evidence was side-lined and scientists and public agencies were subjected to political pressure $^{3}$. A new court case was filed in early 2020 by the Australian Conservation Foundation (an environmental non-governmental organization), to further test the lawfulness of the approvals process for the Adani mine. Secondly, protecting the springs hinges on a series of environmental management plans that Adani must have approved before it can start building the mine. These plans are high-stakes, but they are routinely formulated and approved behind closed doors. If they are not robust, they effectively raze the protections that are intended under conditions of approvals.

The bottom line is: when available evidence is not effectively and transparently incorporated into the approvals process, it undermines both the legitimacy of the approval and the available legal controls intended to protect the environment.

The Adani case study highlights the role of scientific evidence in public-decision making, and the potential to create a negative feedback loop, in which political interference in the creation and use of scientific evidence leads to a weaker evidence base, further reducing reliance on and legitimacy of science for good decisions, in turn leading to increasing political interference. Law provides a way to transition out of this negative loop (Fig. 1). All too often, the connection between science and the law is unfairly labelled as 'green tape'. In reality, the law can, and should, do more to require transparency and accountability for the use of scientific evidence, as well as to quarantine the process of generating that evidence from the political sphere.

Environmental law can promote transparency and efficiency by facilitating 'FAIR' (Findable, Accessible, Interoperable and Reusable ${ }^{4}$ ) environmental data. For example, Australia's national Water Act 2007 requires public and some private entities to provide standardized water data to a central 
agency that aggregates it and makes it public. FAIR data avoids duplicated information gathering, makes the most of available data and encourages consideration of the cumulative impacts of multiple projects - a key problem for the Adani mine.

Law also prescribes the way decision-makers produce and use scientific evidence, by establishing processes for independent experts to review data and transparently advise government decision-makers in the public eye. In the United States, public hearings to ventilate and publicly test expert testimony are common for water rights-related approvals. Around the world, decision-makers use a variety of such initiatives in seeking to enhance the legitimacy of their decisions ${ }^{5}$.

Finally, law can impose substantive standards on which evidence should be used by decision-makers. The US Endangered Species Act 1973 requires decision-makers to use 'best available science', a standard to which courts can hold agencies accountable $^{6}$. What the best evidence is, and how it is created and assessed in different cultural contexts will influence outcomes ${ }^{7}$. To enhance legitimacy, multiple sources of knowledge can, and should, be encompassed within 'best available evidence' standards, and the law should include protocols for empowering historically disenfranchized groups. For example, Indigenous peoples' oral records can provide a data source extending over millennia, which can far outstrip other sources of data ${ }^{8}$.

Ultimately it is the authority conferred by law (by following prescribed processes, ideally including meaningful public engagement) that legitimizes decisions made by political leaders. Maintaining this legitimacy is an ongoing process ${ }^{9}$, and law can support this by: (1) requiring the use of the best available evidence by decision-makers; (2) de-politicizing processes of evidence collection, storage, dissemination and review; and (3) establishing processes of decision-making where the use of that evidence is transparent so that decision-makers can be held accountable (Fig. 1).

Science can help all of us to understand the current and future implications of public decisions. Where those implications manifest over long periods, as with climate change, science helps make them comprehensible in the short term; in faster-moving conditions, as in the current COVID-19 pandemic, transparent scientific data inform (and legitimize) extremely difficult government decisions. Currell et al. highlight the risks of political interference in, and weakening of, scientific evidence that is then relied on by political leaders to justify decisions with potentially disastrous impacts. Harnessing the power of law to support the use of science in decision-making protects the independence and rigour of scientific processes, and requires this evidence to be considered transparently by decision-makers. In doing so, we can also avoid the risk of a negative feedback loop between political interference and weaker scientific evidence.

Erin O'Donnell (D) $₫$ and Rebecca Nelson Melbourne Law School, The University of Melbourne, Melbourne, Victoria, Australia.

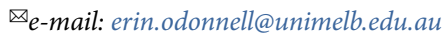

Published online: 11 May 2020

https://doi.org/10.1038/s41893-020-0541-6

References

1. Mora, C. et al. Nat. Clim. Change 8, 1062-1071 (2018).

2. Hornsey, M. J. et al. Nat. Clim. Change 6, 622-626 (2016).

3. Currell, M. J., Irvine, D. J., Werner, A. D. \& McGrath, C. Nat. Sustain. https://doi.org/10.1038/s41893-020-0527-4 (2020).

4. Wilkinson, M. D. et al. Sci. Data 3, 160018 (2016).

5. Bucchi, M. \& Neresini, F. in The Handbook of Science and Technology Studies (eds Hackett, E. J. et al.) 449-472 (MIT Press, 2007).

6. Lowell, N. \& Kelly, R. P. Biol. Conserv. 196, 53-59 (2016).

7. Jasanoff, S. Science and Public Reason (Routledge, 2012).

8. Eisner, W. R. et al. Arctic 62, 429-442 (2009).

9. Hogl, K. et al. (eds) Environmental Governance: The Challenge of Legitimacy and Effectiveness (Edward Elgar, 2012). 